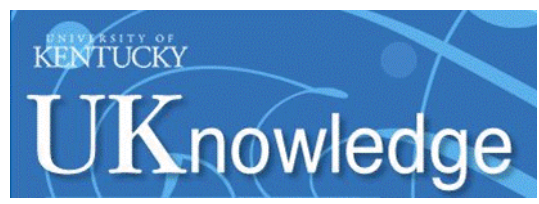

University of Kentucky

UKnowledge

Kentucky Tobacco Research and Development Center Faculty Publications

$7-1-2020$

\title{
Patterns of Inheritance of Acylsugar Acyl Groups in Selected Interspecific Hybrids of Genus Nicotiana
}

Antoaneta B. Mihaylova-Kroumova

University of Kentucky, amihaylo@uky.edu

Ivan Artiouchine

University of Kentucky, isarti0@uky.edu

Victor D. Korenkov

University of Kentucky, vdkore0@uky.edu

George J. Wagner

University of Kentucky, gwagner@uky.edu

Follow this and additional works at: https://uknowledge.uky.edu/ktrdc_facpub

Part of the Plant Sciences Commons

Right click to open a feedback form in a new tab to let us know how this document benefits you.

\section{Repository Citation}

Mihaylova-Kroumova, Antoaneta B.; Artiouchine, Ivan; Korenkov, Victor D.; and Wagner, George J., "Patterns of Inheritance of Acylsugar Acyl Groups in Selected Interspecific Hybrids of Genus Nicotiana" (2020). Kentucky Tobacco Research and Development Center Faculty Publications. 23.

https://uknowledge.uky.edu/ktrdc_facpub/23

This Article is brought to you for free and open access by the Tobacco Research and Development at UKnowledge. It has been accepted for inclusion in Kentucky Tobacco Research and Development Center Faculty Publications by an authorized administrator of UKnowledge. For more information, please contact UKnowledge@lsv.uky.edu. 


\section{Patterns of Inheritance of Acylsugar Acyl Groups in Selected Interspecific Hybrids of Genus Nicotiana}

\section{Digital Object Identifier (DOI)}

https://doi.org/10.1007/s10265-020-01188-x

\section{Notes/Citation Information}

Published in Journal of Plant Research, v. 133, issue 4, p. 509-523.

(C) 2020 Springer Nature Switzerland AG.

This is a post-peer-review, pre-copyedit version of an article published in Journal of Plant Research. The final authenticated version is available online at: https://doi.org/10.1007/s10265-020-01188-x 
Antoaneta B. Mihaylova-Kroumova:

Kentucky Tobacco Research and Development Center, University of KY, 1401 University Dr., Lexington, KY 405460236, USA

Tel.: +1 (001) (859) 257-2409;

Fax: +1 (001) (859) 323-1077

amihaylo@uky.edu

Subject area: Physiology/Biochemistry/Molecular and Cellular Biology

This manuscript contains seven tables, one color figure, and three supplementary figures. 
Antoaneta B. M.-Kroumova, Ivan Artiouchine., Victor Korenkov, George J. Wagner

\section{Patterns of inheritance of acylsugar acyl groups in selected interspecific hybrids of genus Nicotiana}

Kentucky Tobacco Research and Development Center, 1401 University Dr., College of Agriculture, University of Kentucky, Lexington, KY 40546-0236, USA

Abstract

Glandular trichomes on the surface of Solanaceae species produce acyl sugars that are species-, and cultivarspecific. Acyl sugars are known to possess insecticidal, antibiotic, and hormone-like properties, and as such have great potential as a class of naturally occurring pesticides and antibiotics. The objective of this work was to analyze the acyl composition of acyl sugars in the leaf trichome exudate from selected Nicotiana species and to follow the inheritance of acyl content in their hybrids. Trichome exudates were collected, and the acyl profiles of acyl sugars were identified via GC-MS. The variations in acyl group inheritance in the hybrids (a single parent resemblance, missing, complementary, and novel groups) matched the patterns described in the literature for a variety of secondary metabolites. However, we did not find a complementation of major parental acyl groups. Instead, in some hybrids we observed a dynamic change in the proportions of acyl groups, distinguishing the acyl group profiles as novel. We observed paternal (i.e. N. tabacum cv. Turkish Samsun $\times$ N. benthamiana hybrids) and maternal (i.e. N. tabacum cv. Samsun-nn $\times N$. otophora) inheritance patterns, novel acyl profiles (N. excelsior hybrids), and missing acyl groups ( $N$. excelsiana). Selective inheritance of some acyl groups in the hybrids of $N$. benthamiana (4- and 5-methylheptanoic isomers) or N. alata (octanoate) was found. Suggestions are given to explain certain patterns of inheritance. The data presented here contribute to the body of knowledge about the effect of interspecific hybridization on the secondary metabolites by including acylsugar acyl groups that have not been studied previously.

Keywords

Acylsugar acyl groups Genus Nicotiana Inheritance Nicotiana hybrids Trichomes 


\section{Introduction}

Acyl sugars (ASs) are naturally-occurring secondary metabolites that are synthesized mainly by enzymes in the glandular trichomes on the surface of plants from the Solanaceae family. Much of the tobacco literature uses the term sugar esters (SEs) to describe acyl sugars. ASs are known to have important roles in plant defense against numerous pests and pathogens such as insects, aphids, whiteflies, budworms, and hornworms, bacteria and fungi (Cesio et al. 2006; Chortyk et al. 1993; Cutler et al. 1992; Leckie et al. 2012; Liu et al. 1996; Luu et al. 2017; Puterka et al. 2003; Severson 1985a). ASs belong to the group of glycosides in which sucrose, glucose, or fructose moieties are esterified to fatty acids having short $\left(\leq \mathrm{C}_{6}\right)$ and/or medium carbon chain length $\left(\mathrm{C}_{7-12}\right)$, and either straight or branched chain. The structures of ASs and their acyl substitutions have been elucidated and presented in numerous publications (Arrendale et al. 1990; Kaiser et al. 2018; Luu et al. 2017; Severson et al. 1991). Species from the genus Nicotiana in the Solanaceae family include tobacco (Nicotiana tabacum) and wild tobacco relatives (Goodspeed 1954). The ASs of N. tabacum vary from those of the other Nicotiana species with respect to sugar moiety and acyl groups attached to them (Ashraf-Kohorassani et al. 2008; Jia et al. 2013; Leffingwell 1999; Severson et al. 1985a). Tobacco produces sucrose esters, where the esterified acyl groups are short-length $\left(\leq C_{6}\right)$ branched-chain groups with a minor presence of $C_{7}$ groups. Three acyl groups are esterified to the glucose moiety, and an acetyl group may be attached to the glucose and/or fructose. The major acyl groups in burley, Virginia, and flue-cured tobaccos are 2-methyl butyrate (2-MeBut), 3-methyl butyrate (3-MeBut), and acetate (Ac), and in oriental tobaccos the major groups are 3-methyl valerate (3-MeVal) and Ac (Ashraf-Kohorassani et al. 2008; Jia et al. 2013; Leffingwell 1999; Severson et al. 1985a). In some Nicotiana species such as $N$. hesperis, $N$. occidentalis, $N$. alata, N. gosseii, and N. amplexicaulis, glucose esters predominate (Jackson et al. 1998) or are present together with sucrose esters (Matsuzaki et al. 1989). Acyl groups in some wild Nicotiana species such as N. glutinosa, N. occidentalis, N. obtusifolia, and N. alata have up to 10 carbons, which form branched and/or straight chains (Chortyk et al. 1993; Cutler et al, 1992; Haliński and Stepnowski, 2013; Kroumova et al. 2016; Nottingham et al. 1996).

ASs with medium-chain acyl groups $\left(\mathrm{C}_{7-12}\right)$ are more toxic than those with short-chain groups $\left(\mathrm{C}_{2-6}\right)$ to soft bodied arthropods such as budworms, hornworms, aphids, and whitefly (Chortyk et al. 1996; Jackson and Danehower 1996; Jackson et al. 1998; Nottingham et al 1996; Severson et al. 1991; Simonovska et al. 2006; Song et al. 2006) and bacteria (Chortyk et al. 1993; Cutler et al. 1992). Similarly, the medium-chain acyl groups 9- methyl nonanoate (9-MeNon) and decanoate (Dec) from wild tomatoes play an important role in insect resistance (Escobar-Bravo et al. 2016). Synthetic sucrose esters with octanoic acid (Oct) $\left(C_{8}\right)$ have been successfully used against a range of arthropod species in tobacco (Song et al. 2006) and Florida citrus (Michaud and McKenzie 2004; Puterka et al. 2003).

Wild Nicotiana species are a great resource for genetic variability of the ASs. If the medium-chain acids can be introduced into the SEs of tobacco crops, they might enhance pest and insect resistance and consequently contribute to better quality and yield of tobacco leaves. One way of introducing new secondary metabolites is via hybridization. Plant hybridization is a known phenomenon. It is thought that around $70 \%$ of flowering plants originated via hybridization (Arnold 1994; Whitham et al. 1999). Hybridization can result in the introgression of traits, development of new species, and can influence the relationships between plants and their environment (Orians 2000). The effect of hybridization on the secondary product chemistry of hybrids and the impact on herbivore resistance has been the subject of several reviews (Cheng et al. 2011; Lopez-Caamal and Tovar-Sanchez 2014; Orians 2000; Rieseberg and Ellstrand 1993) summarizing 62 studies. The overall conclusion was that hybridization contributes to secondary metabolite diversity and affects herbivore resistance.

The genus Nicotiana comprises about 80 reported species, 57 of which have been shown to hybridize between themselves and with N. tabacum (Barbeć 2015; Lewis 2011). The interspecific crosses thus far have been estimated to number 300 (Barbeć 2015). The abundance of successful interspecific crosses in this genus may be due to "slower evolution of genetic blocks to hybridization than the gene and chromosome alterations" (Goodspeed 1954). Nicotiana hybrids have been explored for a variety of reasons: (1) Initially they were used to study the phylogenetic relationships within Nicotiana (Barbeć 2015; Lewis 2011); (2) Hybridization is used to transfer useful genes from wild, undomesticated relatives into tobacco. These non-tabacum species have been explored for crop 
improvement due to their genetic variability and because some of them harbor novel disease-resistance genes (see Lewis 2011 and the references therein). (3) The cytoplasmic and organelle genomes of wild species have been successfully used as a source of male-sterile cytoplasm (CMS) to increase the efficiency of hybrid seed production of commercial cultivars (Lewis 2011 and the references therein). (4) One important application of Nicotiana hybrids is that they can be advantageous platforms for the production of animal vaccines (Ling et al. 2012; Rice et al. 2013). (5) Intensive hybridization is being conducted within N. tabacum cultivars and introductions to "develop new tobacco hybrid cultivars bearing high yield, good quality, multiple disease resistance, and broad industry acceptability" (Miller, R., https://reeis.usda.gov/web/crisprojectpages/0227012-tobacco-breeding-andgenetics.html). (6) Tobacco hybrids have also been created as sources of genetic variations for trichome-produced secondary metabolites (Nielsen 1989).

Regardless of the broad-spectrum exploration of the Nicotiana hybrids, little attention had been paid to the inheritance of secondary metabolites produced by glandular trichomes, mainly diterpenes and ASs. As an exception, Nielsen (1989) quantitatively compared trichome-produced AS, together with terpenoids [cis-abienol, $\alpha$ - and $\beta$ - cembratriene diols ( $\alpha$ - and $\beta$-CBT-diols)] in tobacco hybrids and their parental species. In contrast, in the genus Lycopersicon from the same family, intense research has been conducted on acylsugars in the hybrids of tomato. The role of ASs against mites and aphids was observed in tomato hybrids after introducing type IV trichomes, a major producer of ASs having 10 carbon acyl groups, from wild tomatoes (Escobar-Bravo et al. 2016; Goffreda et al. 1990; McDowell et al. 2011; Snyder and Carter 1984). Variation in Type IV trichome density, and respectively the abundance of $\mathrm{SE}$, among the individual hybrids correlated with the variation in mite response. Furthermore, hybrids between L. esculentum and L. pennellii were less infested with aphids (Macrosiphum euphorbiae) than the common tomato, due to the increased number of AS-producing trichomes and increased amount of ASs (Carter and Snyder 1985).

We were not able to find accessible literature wherein the acyl composition of acyl sugars in the interspecific Nicotiana hybrids has been reported. Moreover, to our knowledge, introduction of trichome-based pest and insect resistance (due to synthesis of variable ASs) from non-tabacum species into tobacco has not yet been reported.

Majority of the studies related to ASs and AS acyl groups of Nicotiana (and other solanaceous ) species were done on leaves (Ashraf-Khorasani et al 2008; Chortyk et al, 1993; Leffingwell 1999; Matsuzaki et al. 1989, 1992;

Severson et al. 1985b, 1985a, 1991; Simonovska et al., 2006;). Historically, leaves of Nicotiana species have been explored because of their commercial use and high-level accumulation of trichome exudate (5-30\% of dry weight of leaves) playing important role in plant-insect, -microbe interaction (Wagner 1991). Here we analyzed trichome exudates from leaves of selected artificial Nicotiana hybrids and their parents for the presence of novel and variable ASs having medium chain-length, branched and straight-chain acyl groups along with short-chain groups to allow further tests for insecticidal potential. The ASs showing insecticidal properties can be used as templates for biotechnological design of acyl sugars that will improve pest resistance of Nicotiana crops. The variation of AS acyl group inheritance in the hybrids, such as complementary group inheritance, unidirectional inheritance from one of the parents, novel AS acyl group profile, and missing groups, were similar to the patterns described in the literature for a variety of secondary metabolites, including essential oils and phenolic glucosides (Cheng et al. 2011). An interesting phenomenon observed was the selective inheritance of certain acyl groups in the hybrids of $N$. benthamiana or N. alata. The data accumulated here contributes to the body of knowledge of the effect of hybridization on the secondary metabolites by including AS acyl groups that have not been previously studied.

\section{Materials and methods}

\section{Plant materials}

In 2000-2003, numerous interspecific crosses between commercial tobacco (maternal/paternal) and non-tabacum species (maternal/paternal) were performed by Kentucky Tobacco Research and Development Center (KTRDC) (Lexington, KY, USA) personnel to identify interspecific hybrids that could be appropriate for the large-scale production of economically important proteins and that had resistance to common tobacco diseases. Hybrid seeds were created via cross pollination, as described in detail in Zaitlin and Mundell (2006). Hybrid \#s H110, H114, 37, 
87, and $\mathrm{H75}$, were selected due to their potential to have diverse set of acyl groups coming from both parents (Table 1). The horticultural Nicotiana hybrids 'Baby Bella', 'Tinkerbell' and 'Whisper' were purchased from Swallowtail Garden Seeds, CA. Seeds from N. excelsior (KTRDC accession numbers 11-S-19-1 and 90-S-19-2), N. benthamiana (accession number S-6-5), and dark-type tobacco KY 171 were obtained from the KTRDC germplasm collection. N. excelsiana hybrid seeds were provided by Kentucky BioProcessing, Owensboro, KY, USA. N. tabacum cv. Samsun-nn (PI 552748), and N. tomentosiformis (PI 555572) seeds were obtained from the NPGS/GRIN collection. Flue cured Virginia K326 tobacco seeds were kindly provided by F.W. Rickard Seeds, Inc. (Winchester, KY, USA). Seeds of Alatae hybrids were a gift from Dr. Catherine Poisson (Bergerac Seed \& Breeding, France.

\section{Hybrid seeds' germination}

Hybrid seeds from the KTRDC hybrid seed collection were sterilized by incubation in $70 \%$ ethanol for one minute, followed by a 10 -minute incubation in $20 \%$ household bleach, ( $0.3 \%$ sodium hypochlorite aqueous solution) followed by rinsing five times in sterile water to remove all traces of bleach and ethanol. The seeds were then germinated in $95 \times 15 \mathrm{~mm}$ Petri dishes on agar medium containing Murashige and Skoog (MS) salts and microelements ( PlantMedia), Gamborg vitamins (1 ml) (Sigma-Aldrich Co. Ltd.) and high-strength agar (0.56\%) (RPI Corp). Approximately one month later, rooted plantlets were transplanted to Styrofoam float trays containing a medium specially formulated for tobacco (Carolina Choice Peat-Lite Mix). Ten days later fertilizer (Peters 20-10-20, $1.5 \mathrm{~g} \mathrm{I}^{-1}$ ) was added, and the solution was replaced weekly thereafter. Plants were grown there for 3 to 4 weeks, whereupon those with well-established roots were transplanted individually into 4-inch pots. Seeds of the horticultural hybrids were sown on Pro-Mix medium (Premier Horticulture Inc., Canada) in 4-inch pots that were then covered with plastic until germination occurred in a growth chamber. All plants were grown at $22.8^{\circ} \mathrm{C}$ with a $16 \mathrm{~h} / 8 \mathrm{~h}$ light/dark regime and $23 \%$ humidity. After germination, the plastic covers were removed and plants were allowed to grow under the same conditions.

\section{Collection of trichome exudate, butyl ester preparation, and GC-MS analysis}

Trichome exudate was collected from the mid-stem leaves. Collection was done when plants were at a vegetative stage, usually three months post-sowing. The maturation time (the time of flower production) of hybrid plants of different crosses varied, but that of the F1 hybrid plants from the same cross were similar. We have continuously observed that around three months post-sowing the AS acyl composition is stable. Extract collection and AS acyl derivatization with butanol were conducted as described in Severson et al. (1985b) with some modifications. Abundance of SEs varied among species. Four or 8 discs $\left(1 \mathrm{~cm}\right.$ radius) were washed for 1 min with $\mathrm{CH}_{3} \mathrm{CN}$, with these washes vacuum-evaporated to dryness, dissolved in $\mathrm{CHCl}_{3}(1 \mathrm{ml})$, transferred to $1.5 \mathrm{ml} \mathrm{GC}$ vials and dried. Where SEs were in low abundance (e.g. $\mathrm{H} 37$ and $\mathrm{N}$. excelsiana), whole leaves were washed with $\mathrm{CH}_{3} \mathrm{CN}$ for 1 min, the washes were vacuum-evaporated to dryness and dissolved in $\mathrm{CHCl}_{3}(10 \mathrm{ml})$. Polar impurities were removed by twice partitioning with $\mathrm{H}_{2} \mathrm{O}$. Chloroform fractions were evaporated to dryness in $\mathrm{GC}$ vials $(1.5 \mathrm{ml}$ ) (Kroumova et al. 2016). Further saponification, butyl ester derivatization of acyl groups, GC-MS analysis and acyl identification were completed as described previously (Kroumova et al. 2016). AS acyl groups were analyzed as butyl esters. The linear structure of acyl groups detected from all species and hybrids, their full and abbreviated names are given in Fig. S1. For the comparison of major acyl groups between hybrids and their parental species, peak areas were converted to moles using the linear regression equations derived from the calibration curves of standards (Kroumova et al. 2016). In the tables and in the graph the relative abundance of AS acyl groups of the individual plant types was calculated as mol\% of total acyl groups.

\section{Results}

\section{Selection of artificial hybrids}

Hybrids from the Nicotiana collection KTRDC were selected on the basis of parental origin. N. tabacum was a preferred maternal line, in order to have hybrids with good biomass (Ling et al. 2012; Zaitlin and Mundell 2006). 
The other parent was selected because of its biosynthesis of medium length, branched, and straight-chain acyl groups (Table 1). We hypothesized that ASs produced by these hybrids may incorporate acyl groups from both parents. The major acyl groups in hybrids were postulated on the basis of the reviews showing that typically the $F_{1}$ hybrids express parental secondary metabolites (Cheng et al. 2011; Orians 2000). The non-tabacum interspecific hybrids N. excelsior $\times N$. bigelovii were selected for the potential to combine 3-MeVal with straight-chain Oct and heptanoic acid (Hept), and medium-length branched-chain methyl heptanoic isomers (Table 1). Hybrid seeds H110 and $\mathrm{H} 114$ were produced by two independent hybridization events using the same parents. The same applies to the hybrids $\mathrm{H} 75$ and $\mathrm{H} 87$.

\section{AS acyl group profiles}

\section{N. tabacum as an example of natural hybrid between $\mathbf{N}$. sylvestris and $\mathbf{N}$. tomentosiformis}

An example of natural hybridization, the species $N$. tabacum originated from an interspecific hybrid between an ancestor of $N$. sylvestris and a particular ancestral lineage of $N$. tomentosiformis (and possibly $N$. otophora), that evolved hundreds of thousands of years after polyploidization (Gray et al. 1974; Lewis 2011). Table 2 compares the acyl composition of the modern parental species and two modern varieties of tobacco - oriental tobacco cv. Samsun-nn and the flue-cured Virginia tobacco cultivar K326. In N. sylvestris the major acyl group is acetate, followed by 4-methyl hexanoate (4-MeHex); 3-MeVal is a minor acyl group. N. tomentosiformis SEs contain high amounts of 3-MeVal, followed by acetate and 2-MeBut. The acyl composition data for N. tomentosiformis is very similar to that already published by Severson et al. (1985b). Samsun-nn has the typical oriental-type profile, where 3-MeVal is the major group, followed by Ac and 2- and 3-MeBut, while Virginia K326 (air-cured type) tobacco has mostly Ac and 2-and 3-MeBut. AS acyl composition data for Samsun-nn and Virginia K326 presented here are in agreement with the literature (Kallianos 1976; Leffingwell 1999; Severson et al. 1985b). With respect to the presence of 3-MeVal as a major acyl group and absence of MeHex isomers, Samsun-nn resembles $N$. tomentosiformis. In Virginia K326, 3-MeVal is substantially reduced, but 2-and 3-MeBut that are present at lower abundances in the parental SEs became second and third major groups, after the Ac (Table 2). We suggest that a mutation in the isopropylmalate synthase gene (IPMS) (reaction 1, Fig. S3) in Virginia causes accumulation of precursor molecules and increased synthesis of 2-MeBut. Other changes are involved as well, leading to the final acyl profile. The presence of 3-MeVal as a major group in both N. tomentosiformis and N. tabacum Samsun-nn, and the lack of MeHex isomers favors the paternity of $N$. tomentosiformis vs. N. otophora, where MeHex isomers are the major groups (See N. otophora data in Table 4).

\section{Artificial N. tabacum hybrids}

\section{N. tabacum cv. Samsun-nn $\times$ N. benthamiana (H110 and H114)}

These hybrids were generated from two independent hybridization events using the same parents. The phenotypes of the hybrids are shown in Fig. 1a, b. Three plants from each hybrid were analyzed, and the data are presented in Table 3. The acyl compositions among individual plants of each cross were consistent, with some variation detected in the relative amounts. The acyl profiles consisted mainly of 6- and 5-MeHept, with small amounts of 5- and 4-MeHex.The other groups were minor. The similarity among AS acyl profiles of individual plants from either hybrid is not surprising because the $F_{1}$ plants were derived from the same hybridization event. What is more interesting is that the acyl composition from the second, independent cross of the same species gave a very similar qualitative acyl profile. We would expect some variations, due to the stochastic separation of chromosomes during the meiosis in both parental species, and respectively different combination of allelic chromosomes. The data from the three individual hybrid plants from each cross are compared with the parental compositions data (Table 3). Parental AS acyl group profiles reported here are in agreement with the published literature (Chortyk et al. 1993; Matsuzaki et al. 1992; Severson et al. 1991). The maternal donor - N. tabacum cv. Samsun-nn synthesizes predominantly 3-MeVal and 3-MeBut, while $N$. benthamiana (paternal donor) makes predominantly 5-and 6-MeHept and the minor acyl groups 4-MeHex and 5-methyl hexanoate (5-MeHex) (Table 3). The hybrids' AS acyl group profiles matched the paternal N. benthamiana profile - with a prevalence of 5- and 6MeHept acids (90\%) and small amounts of 4- and 5-MeHex. All parental groups were present in the hybrids, but no 
combination of the major acyl groups 3-MeVal and MeHept isomers occurred. 3-MeVal was present as a minor group.

\section{N. tabacum $\times$ N. otophora hybrids (H75 and H87)}

The maternal parent of hybrid H75 is a 'dark type' tobacco cv. SN2108, and the maternal parent of hybrid H87 is the flue-cured tobacco cv. NC 297 (Table 1). The phenotype of the hybrids is shown in Fig. 1c, d. The AS acyl composition of the hybrids and the parental species is presented in Table 4. N.tabacum KY171 (dark type) and N. tabacum K326 (flue cured) shown in Table 4 are not the exact maternal species, but they are representatives of the dark and flue-cured class of tobaccos. For each hybrid, three individual plants were analyzed. Compositionally, the acyl profile was very similar among the $F_{1}$ plants of the same hybrid and between the individuals of the two hybrids. 3-MeVal was the predominant group, followed by 3-and 2-MeBut. There was some variability in the relative abundance among the individual plants of each hybrid. Still, when comparing the average values of individual acyl groups and their total distribution it is clear that there is a great similarity in ASs acyl group composition between the two hybrids (Table 4). The acyl profiles of the maternal species - dark tobacco (for H75) and flue-cured (for $\mathrm{H} 87$ ) tobaccos are also similar. Dark and flue-cured tobaccos were previously shown to produce ASs containing mostly 2-and 3-MeBut and Ac (Leffingwell 1999; Severson et al. 1985a). The major AS acyl groups of N. otophora are 4- and 5-MeHex and 3-MeVal (in declining order) (Severson et al. 1991). All parental acyl groups were inherited in the hybrids. 3-MeVal became a major group followed by small amounts of 2- and 3-MeBut. Some $F_{1}$ plants showed elevated abundances of MeHept isomers that otherwise were minor groups in N.t. K326 or were not detected in N.t. KY171. Thus, by crossing dark or flue-cured tobacco with N. otophora, the hybrids acquired novel AS acyl chemistry resembling oriental-type tobacco profile, but with additional eight-carbon branched-chain groups and missing Ac groups (Table 4).

\section{Artificial hybrids of $N$. excelsior}

\section{Hybrid H37}

This hybrid is a cross between $N$. excelsior and $N$. bigelovii. The maternal parent, N. excelsior, is a leafy herb with mostly glabrous leaves and stems (http://www.flora.sa.gov.au/efsa/lucid/Solanaceae/Nicotiana\%20species/key/Australian\%20Nicotiana\%20species/ Media/Html/Nicotiana excelsior.htm). The paternal species, N. bigelovii (or N. quadrivalvis) (Knapp et al. 2004) is a bushy herb, with small-lamina leaves and numerous glandular trichomes (nathistoc.bio.uci.edu/plants/Solanaceae/Nicotiana\%20quadrivalvis.htm). The hybrid plants were small in size with mostly glabrous leaves, resembling the maternal parent (Fig. 1e). The hybrids produced very little exudate as judged by the slight leaf stickiness and by the low relative abundance as revealed by GC-MS. The acyl composition was similar among the individual $\mathrm{F}_{1}$ plants, comprising mostly 5- and 6-MeHept, followed by MeHex isomers and 3MeVal. Comparison of the AS acyl groups between the parents and hybrids is shown in Table 5. We possessed two accession of $N$. excelsior. The precise maternal accession of Hybrid 37 was not given. That's why we analyzed both accession. High similarity of the acyl profile was observed between them with some differences in the proportion of groups (Table 5). N. excelsior SEs contained mostly Oct, 5-MeHept, Hept, and 2-MeBut while N. bigelovii synthesized mostly 3-MeVal, 2-MeBut, and Ac (Matsuzaki et al. 1989). Synthesis of the straight-chain groups Oct and Hept was not transferred maternally to the hybrids. Qualitatively, the acyl composition of F1 plants was closer to the paternal species $N$. bigelovii. However, the relative abundance of individual acyl groups varied substantially from N. bigelovii, which resulted in a novel acyl profile (Table 5). This profile showed substantial presence of medium length, branched-chain groups ( $75 \%$ of all acyl groups). Variability was observed among the individual hybrid plants. More study is needed to address this variability. Regardless of the extract's insecticidal potential due to the predominance of medium-length, branched-chain (MeHept and MeHex) isomers, the scarce yield makes the extract unsuitable for further examination. However, the exudate of the maternal species, N. excelsior, can be explored further as the acyl profile consists mostly of MeHex isomers and medium-length straight-chain groups (>72\% of total acyl groups).

\section{N. excelsiana}


N. excelsiana is a fertile tetraploid hybrid derived from crossing $N$. excelsior and $N$. benthamiana that was created for the purpose of vaccine production (i.e. Ling et al. 2012). Like the maternal species N. excelsior, the hybrid is leafy with mostly glabrous leaves (Smith et al. 2009). The only AS acyl groups observed were 5- and 6-MeHept (Table 5). The comparison between parental species and $N$. excelsiana showed that the 6-MeHept group was inherited paternally from N. benthamiana, but 5-MeHept may have come from either parent. The straight-chain groups Hept and Oct from N. excelsior were not inherited in the hybrid. The acyl profile of ASs from N. excelsiana can be considered novel, consisting only of two acyl groups. The $N$. excelsiana AS acyl profile shows an example of missing secondary metabolites (Table 5). The trichome extract would be a good source for testing the insecticidal potential of MeHept isomers provided that a sufficient amount of SEs could be collected.

\title{
Artificial interspecific hybrids from section Alatae
}

\author{
N. $\times$ sanderae \\ $N$. $\times$ sanderae originated from a cross between $N$. alata and $N$. forgetiana (Chase et al. 2003). Images of this hybrid \\ can be found on the web (https://www.alamy.com/flowering-tobacco-nicotiana-x-sanderae-nicotiana-sanderae- \\ potted-plants-image9257554.html). N. alata is the species from which most of the modern horticulture hybrids are \\ derived (http://portlandnursery.com/plants/annuals/Nicotiana.shtml). N. alata synthesizes straight-chain, short \\ and medium length acyl groups with up to eight carbons, and also short length, branched-chain, acyl groups with \\ up to six-carbons (Table 6). In contrast, $N$. forgetiana has predominantly branched-chain groups with up to seven \\ carbons (Severson et al. 1991). The comparison of $N . \times$ sanderae and its parents is shown in Table 6 . The hybrid's \\ major groups are Oct, 2-MeBut, and Ac, followed by Hex. The maternal species $N$. alata produces the same major \\ groups. Straight-chain groups Hex and Oct are inherited from N. alata, but Ac and 2-MeBut may have been \\ inherited from either parent. MeHex isomers that are the second and third major acyl groups of $N$. forgetiana \\ were not detected in the hybrid. The $N . \times$ sanderae AS acyl group composition was confirmed, and AS structures \\ were elucidated by British American Tobacco, Inc., Souza Cruz, Brazil (Guilherme Sabin , personal communication).
}

\section{Alatae hybrids}

The Alatae hybrids were created by Catherine Poisson (Bergerac Seed \& Breeding SC, France) by crossing two inbred lines. These lines originated from a breeding program that started by crossing wild species from section Alatae ( $N$. langsdorffii, N. alata, N. forgetiana, N. x sanderae), but for some of them commercial varieties were additionally involved. However, the hybrids are not direct progenies of the original wild species and commercial varieties, as many crosses and backcrosses have been done through the years (Poisson Catherine, personal communication). We analyzed 15 hybrid lines (Fig. S2) and found their AS acyl group compositions to be similar. In hybrids PO\# $67,15,69,70,81,101$, and 120 , Oct was the predominant group (>50 \% of total acyl groups) (Fig. S2, Table 6 ) and the other groups were $\leq 10 \%$ each. In hybrids PO\# 5, 33, 71, 72, 94, and 96, Oct was the major group followed by 2-MeBut. In all hybrids there was a presence of other then $C_{8}$ straight-chain groups $\left(C_{4}, C_{6}, C_{7}\right.$, and $\left.C_{9}\right)$, and the total relative abundance of straight-chain groups in all hybrids was $60-90 \%$. 2- and 3-Mebut were absent in POs 70, 111 and 112. There was variation in the relative acyl abundance between individual plants of each PO hybrid, but nevertheless the acyl profiles of the lines were well defined. The composition of PO5, 33, 71, 72, 94, and 96 hybrids was closer to that of $N$. sanderae and $N$. langsdorffii (Table 6). In section Alatae only N. alata and N. langsdorffii synthesize Oct, and therefore this acyl group could have been inherited from either of the species. MeHex isomers from $N$. forgetiana were not inherited during the breeding process. Acetate was not inherited from N. alata or N. $x$ sanderae as well. Hept and Non groups were not present in the parental species, so they may be novel chemicals in the hybrids. The ASs of hybrids synthesizing mostly octanoic acid can be tested for insecticidal activity.

\section{"Tinkerbell", "Baby Bella" and "Whisper"}

The ornamental hybrids "Tinkerbell" (Nicotiana alata "Tinkerbell"), Nicotiana $\times$ hybrida "Baby Bella" (Nicotiana $\times$ sanderae "Baby Bella") and "Whisper" are highly disease-tolerant hybrids that have a notable pleasant aroma and attractive petal colors (https://www.gardenersworld.com/plants/nicotiana-alata-tinkerbell/; 
http://www.robsplants.com/plants/NicotSande; http://floranova.com/products/Nicotiana/; https://portlandnursery.com/annuals/nicotiana/). These hybrids possess the most diverse AS acyl profiles compared to the other studied hybrids. Seventeen acyl groups were detected (Table 7). The hybrids' AS acyl composition was qualitatively similar, consisting mostly of Oct, and 2-MeBut (40 to $50 \%$ of total acyl groups) along with numerous but minor ( $<10 \%$ each) straight-chain acids $\left(C_{3,4,6-12}\right)$ and branched-chain acids (MePro, 3-MeBut, MeVal, 4-MeHex and MeHept isomers).The acyl composition was similar to that of $N$. alata, and $N$. $\times$ sanderae, but it was enriched with six additional groups (Table 7). Hept, Non, Dec and Laur acyl groups may be novel for all the hybrids. There was variability in the relative proportions of AS acids among individual plants and among the hybrids. Oct was more prominent in "Baby Bella", while in "Tinkerbell" 2-MeBut was a predominant group followed by Oct and Ac. In "Whisper" the proportions between Oct and 2-MeBut varied from plant to plant (Table 7). MeHex isomers were found in the "Whisper" plants, but not in "Thinkerbell". In "Baby Bella" MePro varied from 0.5 to $13.8 \%$. Oct varied from 7.2 to $34.5 \%$ in "Thinkerbell", and from 12 to $45 \%$ in "Wispers" (Table 7 ). Regarding the abundance of major acyl groups, the acyl compositions of "Tinkerbell" was more similar to N. alata, while "Baby Bella" acyl composition was more similar to $N$. $\times$ sanderae.

\section{Discussion}

In this work, we studied the inheritance of the trichome-produced AS acyl groups in interspecific hybrids in the genus Nicotiana for the purpose of finding unique acyl compositions, combining diverse acyl groups from both parents. Of great interest was the inheritance of medium-length, straight or branched-chain groups as major groups in the ASs because they have been shown to be more toxic to arthropod pests (Escobar-Bravo et al. 2016; Jackson and Danehower 1996; Jackson et al. 1998; Severson et al. 1991b; Simonovska et al. 2006; Song et al. 2006).

The parental species of Nicotiana hybrids have diverse acyl profiles. The combined genomes in the hybrids would carry all the genes necessary for synthesis of ASs and AS acyl groups featured in both parents and the interaction between the alleles from both genomes will determine the final profile in the hybrids. There is not sufficient knowledge about the genes and the regulatory factors participating in the synthesis of ASs in the genus Nicotiana to satisfactorily explain the observed patterns of inheritance. Figure S3 shows suggested $\alpha$-KAE pathways for the synthesis of acyl-CoA groups (Kroumova et al. 1994) in some species of genus Nicotiana and in petunia. The pathways for the acyl groups' synthesis were concluded for N. glutinosa, N. gossii, and N. bentamiana (Kroumova et al. 2003). Numerous acyltransferase genes that play roles in acyl sugar assembly have been discovered among the species of genus Solanum and in petunia (Moghe et al. 2017; Nadakuduti et al. 2017) but orthologous acyltransferase genes have not been reported in Nicotiana species. We hypothesize that IPMS enzyme(s) (reaction 1, Fig. S3), branched-chain $\alpha$-keto acid dehydrogenase (BCKD) enzyme(s) (reaction 3, Fig. S3), and putative acyltransferases (reaction 4, Fig. S3) play roles in determination of the uniqueness of acyl groups in individual species, and for the variability in acyl sugar compositions commonly observed. Trichome-specific IPMS (reaction 1, Fig. S3) from N. tabacum has been characterized and was shown to be essential for the synthesis of 3-MeVal (Gwynn et al. 1985; https://www.lens.org/lens/patent/EP_2565265_A1), while the tomato E1-B subunit of BCKD (reaction 3, fig. S3) was shown to affect branched-chain acyl groups in $N$. benthamiana (Slocombe et al. 2008). It is clear however, that many more genes are potentially relevant to AS acyl chain synthesis and ASs assembly, keeping in mind the great variability of ASs in the numerous Nicotiana species, and taking into consideration the voluminous work on the synthesis of ASs in the genus Solanum in recent years (Fan et al. 2016; Ning et al., 2015; Schilmiller et al. 2015, 2016). Genes involved in the metabolism of ASs have been studied extensively in solanaceous crops because of their important role in plant defense and also for the purpose of increasing AS-mediated pest resistance (Glas et al. 2012; Mandal et al. 2018; Moghe et al. 2017). Acyl sugar chemistry modification has been achieved in tomato by introducing individually, or in combination, several quantitative trait loci (QTLs) from S. pennellii. The introduction of more than one trait altered the abundance of total SE, the acyl group profile, and the diversity of SE due to the additive and epistatic interactions between the QTLs featuring certain genes (Leckie et al. 2012; Smeda et al. 2017).

Regardless of the potential participation of numerous genes in the synthesis of acyl groups and ASs assembly, it has been proposed that in the hybrids, in general, one or few genes exhibiting dominance/recessivity regulate the 
expression of secondary compounds (Gwynn et al. 1985; Lopes-Caamal and Tovar-Sanches 2014). Inheritance of some of the acyl groups in Nicotiana hybrids fits such a proposition, and is discussed below.

We have observed several patterns of AS acyl group inheritance (chemistry resembling that of a single parent, complementary acyl groups, missing acyl groups, and novel groups) that matched the patterns described by others for a variety of secondary metabolites, including essential oils, phenolic glucosides, cembratriene diols (CBT-diols), alkaloids, fatty acids, and phenolic constituents (Cheng et al. 2011; Court et al. 1992; Orians 2000). In addition, we observed variability in the expression of individual acyl groups. According to the literature, the first-generation hybrids $\left(F_{1}\right)$ usually express both parental secondary metabolites (complementary expression) (Cheng et al. 2011; Rieseberg and Ellstrand 1993; Orians 2000), which is why our expectations were for the hybrid ASs to combine a variety of acyl groups in substantial abundance. In this study, complementary inheritance was observed but the expected abundance was not. In hybrids 110 and 114, all acyl groups were present, but Ac and MePro were not synthesized in the abundance that corresponded to that of the parental species. The overall acyl group profile of $\mathrm{H} 110$ and $\mathrm{H} 114$ resembled that of $\mathrm{N}$. benthamiana (paternal inheritance) (Table 3). Similarly, it has been shown that in some Nicotiana hybrids the flower color was sometimes closer to one of the parents (Ling et al. 2012; Patel et al. 2011; Pental et al. 1984). When dark or flue-cured tobacco was crossed with $N$. otophora, the $\mathrm{F}_{1}$ hybrids (H75 and H87) also had the acyl profile of both parents. However, the ratio of acyl groups and the major acyl groups did not resemble the profile of either parent (Table 4) but were similar to that of the oriental tobacco. We suggest that the strong reduction in 4-MeHex and the robust synthesis of 3-MeVal (already present in low abundance in the parents) in the hybrids may be caused by an isoform of IPMS (reaction 1, Fig. S3). Both acyl groups are products of the ante-iso branch of the $\alpha$-ketoacid elongation pathway ( $\alpha$-KAE) (Fig. S3), where one cycle of elongation produces 3-MeVal, and two cycles produce 4-MeHex (Kroumova and Wagner 2003). The IPMS gene for synthesis of 4-MeHex in N. otophora may be in a heterozygous state, in which the dominant allele was not inherited in both hybrids, thus leading to the accumulation of the precursor 2-oxo-4 MeHex for synthesis of 3-MeVal.

The 5-and 6-MeHept groups produced by N. benthamiana were also inherited in N. excelsiana (Table 5). We hypothesize that in $N$. benthamiana both alleles of the putative gene(s) responsible for synthesis of MeHept isomers are in a dominant state, causing synthesis to occur in the hybrid. We think that one candidate gene important for the presence of MeHept in ASs is BCKD that is involved in branched-chain amino acid degradation and is potentially relevant to AS branched-chain acid synthesis (Slocombe et al. 2008). After BCKD E1-ß silencing (reaction 3, Fig. S3) in N. benthamiana, a significant reduction in 5- and 6-MeHept was observed, while in $S$. pennellii, reduction was observed in the synthesis of MePro and 8-MeNon (Slocombe et al. 2008). Acyltransferase genes can be involved as well. Acyltransferases were shown to contribute to acylsugar diversity in the genus Solanum (Schilmiller et al. 2015). We suggest that in the genus Nicotiana, genes orthologous to those in Solanum may participate in the assembly of acylsugars.

In hybrid $\mathrm{H} 37$ (N. excelsior $\times N$. bigelovii), Hept and Oct were not inherited, while 6-MeHept became a second major group in contrast to both parents where it had a minor presence. MeHex isomers were also elevated compared to their minimal presence in both parents (and 6-MeHept). We suggest that in this particular hybrid, ASAT enzymes may be involved (reaction 4, Fig. S3).

The Oct group from N. alata was inherited in the hybrids regardless of the SE acyl composition of the other parent. We hypothesize that, similar to MeHept in N. benthamia, the gene(s) important for Oct synthesis is in a homozygous dominant state and the inheritance is manifest in the hybrids. In contrast, Oct and Hept from $N$. excelsior, and 4-and 5-MeHex from N. forgetiana or N. otophora, were not inherited. It is possible that the genes involved in the synthesis of these groups are in a heterozygous state, and that the hybrids inherited the recessive allele (or the allele that is not functional). Acetate was not inherited in the Alatae hybrids. Most likely this may be related to acetyl-specific acyltransferase.

The appearance of novel acyl groups was observed, interestingly, only in Alatae hybrids and in the horticulture hybrids. The horticulture hybrids are also related to Alatae parents, and we may suggest that the novel groups are features in Alatae hybrids. Orians (2000) indicated that novelty may be more common for plants that produce chemicals in specialized cells, i.e. glandular trichomes. These novel acyl groups (together with Hex and Oct that are 
present in the parental species) may have come from the straight-chain branch of the $\alpha$-KAE pathway (Fig. S3) as in petunia and $N$. gossei (Kroumova and Wagner 2003). It is also possible to be synthesized by fatty acid elongation path, via two-carbon elongation, characteristic of fatty acid biosynthesis (Kroumova and Wagner 2003; Walters and Steffens 1990).

The data presented in this paper show variability in acyl group inheritance in Nicotiana $\mathrm{F}_{1}$ hybrids, and thus acyl profile prediction based on the chemotypes of the parental species could be inaccurate. Hybrids may inherit the acyl groups from both parents, but it is important also which acyl groups are in abundance and which groups will contribute to the pest resistance or will improve the hybrid fitness in the environment. In N. tabacum cv. Samsun$\mathrm{nn} \times N$. benthamiana hybrids, 3-MeVal and MeBut isomers became minor groups. Similar changes were observed for Ac, MeBut isomers, and MeHex isomers in hybrids 75 and 87, while MeHept isomers were slightly increased (Table 4). Straight-chain groups from $N$. excelsior were not inherited. In contrast, in $N$. $\times$ sanderae, the straightchain acyl groups Hex and Oct were inherited maternally from $N$. alata. The horticulture hybrids are said to be highly disease-tolerant (www.plant-world-seeds.com), and we assume that Oct contributes to this resistance. Synthetic sucrose octanoate esters have strong pesticidal and insecticidal effects (Michaud and McKenzie 2004; Technical Evaluation Report Sucrose Octanoate Esters 2005). The natural octanoate-containing ASs are synthesized in the species from section Alatae (Chortyk et al. 1993; Cutler et al. 1992; Kroumova et al. 2016, and current work). Thus, octanoic acid could be a good candidate for introgression into tobacco.

We did not find any correlation between the parental origins of individual acyl groups and their inheritance in hybrids. In N. tabacum cv. Samsun-nn, hybrids 110/114, and N. excelsiana, the inheritance of the major acyl groups was paternal. In N. x sanderae inheritance was maternal, while in $\mathrm{H} 75$ and $\mathrm{H} 87$ (N. tabacum $\times$ N. otophora) and in $\mathrm{H} 37$ the acyl profiles did not match either parent with respect to the major acyl groups.

This study shows different patterns of inheritance of AS acyl groups, and additional work is needed to further guide preparation of interspecific hybrids to provide sufficient amounts of unusual ASs in order to test their insect and disease resistance potential. Knowledge of the way that particular acyl groups function in plant protection could help increase trichome-based resistance in N. tabacum.

\section{Acknowledgments}

We thank the KTRDC (Lexington, KY, USA) and Dr. Dave Zaitlin from the same organization for providing hybrid seeds and seeds of $N$. excelsior, $N$. benthamiana and $N$. tabacum KY171. We thank Dr. Zaitlin for the critical review of the manuscript and the useful suggestions. We thank Kentucky BioProcessing (Owensboro, KY, USA) for kindly providing N. excelsiana hybrid seeds. We give special thanks to Dr. Catherine Poisson (Bergerac Seed \& Breeding, France) for her kind gift of Alatae hybrid seeds. We are grateful to Dr. Jessica Nifong from the NPGS/GRIN collection, USDA for N. tabacum cv. Samsun-nn (PI 552748) and N. tomentosiformis (PI 555572) seeds, and to F.W. Rickard Seeds Inc. (Winchester, KY, USA) for N. tabacum Virginia K326 seeds.

\section{Funding}

This work was supported by the KTRDC, University of Kentucky, Lexington, KY, USA.

\section{Conflict of Interest}

The authors declare that they have no conflict of interest.

\section{References}


Arnold M (1994) Natural hybridization in Louisiana irises. BioScience 44: 141-147._doi:10.2307/1312250

Ashraf-Khorasani M, Nazem N, Taylor L.T, Coleman WM (2008) Isolation, fractionation, and identification of sucrose esters from various oriental tobaccos employing supercritical fluids. Beitrage zur Tabakforschung International/ Contributions to Tobacco Research. 23: 32-45. doi: 10.2478/cttr-2013-0846

Barbeć A (2015) Nicotiana hybridization map - "blank spots" yet to be filled. CORESTA, AP28, Quebec, Canada Carter CD, Snyder JC (1985) Mite response in relation to trichomes of Lycopersicon esculentum x L. hirsutum F2 hybrids. Euphytica 34: 177-185. https://doi.org/10.1007/BF00022877

Cesio V, Dutra C, Moyna R, Heinzen H. (2006) Morphological and chemical diversity in the Type IV glandular trichomes of Solanaceae (S. sisymbrifolium and $N$. glauca) as germplasm resources for agricultural and food use. Electron J Biotechnol 9: 282-285 http://www.ejbiotechnology.info/content/vol9/issue3/full/4/; DOI: 10.2225/vol9-issue3-fulltext-4.

Chase MW, Knapp S, Cox AV, Clarkson JJ, Butsko Y, Joseph J, Savolainen V, Parokonny AS (2003) Molecular systematics, GISH and the origin of hybrid taxa in Nicotiana (Solanaceae). Ann Bot 92: 107-127

Cheng D, Vrieling K, Klinkhamer PG (2011) The effect of hybridization on secondary metabolites and herbivore resistance: implications for the evolution of chemical diversity in plants. Phytochem Rev 10: 107-117. doi: 10.1007/s11101-010-9194-9

Chortyk OT, Severson RF, Cutler HC, Sisson VA (1993) Antibiotic activities of sugar esters isolated from selected Nicotiana species. Biosc Biotechnol Biochem 57: 1355-1356 doi: http://dx.doi.org/10.1271/bbb.57.1355

Chortyk OT, Pomonis JG, Johnson AW (1996) Syntheses and characterizations of insecticidal sucrose esters. J Agr Food Chem 44: 1,551-1,557. https://doi.org/10.1021/jf950615t

Court WA, Brandle JE, Pocs R, Hendel JG (1992) The chemical composition of somatic hybrids between Nicotiana tabacum and N. debneyi. Can J Plant Sci 72: 209-215. https://doi.org/10.4141/cjps92-021

Cutler HG, Severson RF, Cole PD, Sisson VA, Jackso, D, Stephenson MG (1992) The biological activity of some mixed sucrose and glucose esters from exotic tobacco cultivars. PGRSA Quart 20: 18-28

Escobar-Bravo R, Alba JM, Pons C, Granell A, Kant MR, Moriones E, Fernández-Muñoz R (2016) A jasmonateinducible defense trait transferred from wild into cultivated tomato establishes increased whitefly resistance and reduced viral disease incidence. Front Plant Sci 7: 1732

Fan P, Miller AM, Schilmiller AL, Liu X, Ofner I, Jones AD, Zamir D, Last RL (2016) In vitro reconstruction and analysis of evolutionary variation of the tomato acylsucrose metabolic network. Proc Natl Acad Sci U S A 113: E239-48. doi: 10.1073/pnas.1517930113

Goffreda JC, Steffens JC, Mutschler MA (1990) Association of epicuticular sugars with aphid resistance in hybrids with wild tomato. J Am Soc Hort Sci 115: 161-165

Goodspeed TH (1954) The Genus Nicotiana: origins, relationships and evolution of its species in the light of their distribution, morphology and cytogenetics. Waltham, Mass.: Chronica Botanica Company

Gray J C, Kung SD, Wildman SG, Sheen, SJ (1974) Origin of Nicotiana tabacum L. detected by polypeptide composition of Fraction I protein. Nature 252: 226-227

Gwynn GR, Severson RF, Jackson DM, Stephenson MG (1985) Inheritance of sucrose esters containing ßmethylvaleric acid in tobacco. Tobacco Sci 29: 79-81

Haliński ŁP, Stepnowski P (2013) GC-MS and MALDI-TOF MS profiling of sucrose esters from Nicotiana tabacum and N. rustica. Z Naturforsch 68: $210-222$

Jackson D, Chortyk O, Stephenso, M, Johnson A, Harlow C, Simmons A, Sisson V (1998) Potential of Nicotiana species for production of sugar esters. Tob Sci 42: 1-9

Jackson D, Danehower D. (1996) Integrated case study: Nicotiana leaf surface components and their effects on insect pests and disease. In: Kerstiens G (ed) Plant cuticles: an integrated functional approach. Chapter: 12. BIOS Scientific Publishers, Oxford, pp 231-254

Jia C, Wang W, Zhu Y, Xu C, Mao D. (2013) Preparative isolation and structural characterization of sucrose ester isomers from oriental tobacco. Carbohydr Res 372: 73-77

Kaiser S, Dias JC, Ardila JA, Soares FLF, Marcelo MCA, Porte LMF, Gonçalves C, Canova Ldos S, Pontes OFS, Sabin GP (2018) High-throughput simultaneous quantitation of multi-analytes in tobacco by flow injection coupled to high-resolution mass spectrometry. Talanta 190: 363-374 
Kallianos AG (1976) Phenolics and acids in leaf and their relationship to smoking quality and aroma. Rec Adv Tob Sci 2: 61-69

Knapp S, Chase MW, Clarkson JJ (2004) Nomenclatural changes and a new sectional classification in Nicotiana (Solanaceae). Taxon 53: 73-83. https://doi.org/10.2307/4135490

Kroumova AB, Xie Z, Wagner GJ (1994) A pathway for the biosynthesis of straight and branched, odd- and evenlength, medium-chain fatty acids in plants. Proc Natl Acad Sci U S A 91:11437-41.

Kroumova AB, Wagner GJ (2003) Different elongation pathways in the biosynthesis of acyl groups of trichome exudate sugar esters from various solanaceous plants. Planta 216: 1013-1021 https://doi.org/10.1007/s00425-002-0954-7 2003

Kroumova ABM, Zaitlin D, Wagner GJ (2016) Natural variability in acyl moieties of sugar esters produced by certain tobacco and other Solanaceae species. Phytochemistry 130: 218-227 http://dx.doi.org/10.1016/i.phytochem.2016.05.008

Leckie BM, DeJong DM, Mutschler MA (2012) Quantitative trait loci increasing acylsugars in tomato breeding lines and their impacts on silverleaf whiteflies. Mol Breeding 31: 957-970

Leffingwell JC (1999) Basic chemical constituents of tobacco leaf and differences among tobacco types In: Davis DL, Nielsen MT (Eds) Tobacco production, chemistry and technology, CORESTA, Blackwell Science Ltd, distributed by lowa State University Press, Ames, lowa, pp 265-284

Lewis RS (2011) Nicotiana. In: Kole C (Ed) Wild crop relatives: genomic and breeding resources, plantation and ornamental crops. Springer-Verlag, Berlin, Heidelberg, pp 185-208. DOI: 10.1007/978-3-642-21201-7_10

Ling .-Y, Edwards AM, Gantier MP, DeBoer, KD, Neale AD, Hamill JD, Walmsley AM (2012) An interspecific nicotiana hybrid as a useful and cost-effective platform for production of animal vaccines. PLoS ONE 7: e35688. https://doi.org/10.1371/journal.pone.0035688

Liu T-X, Stansly PA, Chortyk OT (1996) Insecticidal activity of natural and synthetic sugar esters against Bemisia argentifolii (Homopetera: Aleyrodidae). J Econ Entomol 89: 1233-1239 https://doi.org/10.1093/jee/89.5.1233

López-Caamal A, Tovar-Sánchez E, (2014) Genetic, morphological, and chemical patterns of plant hybridization, Rev Chil Hist Nat 87: 16 https://doi.org/10.1186/s40693-014-0016-0

Luu VT, Weinhold A, Ullah Ch, Dressel S, Schoettner M, Gase K,Gaquerel E, Xu S, Ian T, Baldwin IT (2017) O-Acyl sugars protect a wild tobacco from both native fungal pathogens and a specialist herbivore. Plant Physiol 174: 370-384. DOI:10.H1104/pp.16.01904

Mandal S, Ji W., McKnight TD (2018) Candidate gene networks for acylsugar metabolism and plant defense in wild tomato Solanum pennellii. https://doi.org/10.1101/294306

Matsuzaki T, Shinozaki Y, Hagimori M, Tobita T, Shigematsu H, Koiwai A (1992) Novel glycerolipids and glycolipids from the surface lipids of Nicotiana benthamiana. Biosc Biotech Biochem 56: 1565-1569. http://dx.doi.org/10.1271/bbb.56.1565

Matsuzaki T, Shinozaki Y, Suhara S, Ninomiya M, Shigematsu H, Koiwai A (1989) Isolation of glycolipids from the surface lipids of Nicotiana bigelovii and their distribution in Nicotiana species. Agric Biol Chem 53: 30793082

McDowell ET, Kapteyn J, Schmidt A, Li C, Kang JH, Descour A, Shi F, Larson M, Schilmiller A, An L, Jones AD, Pichersky E, Soderlund CA, Gang DR (2011) Comparative functional genomic analysis of solanum glandular trichome types plant. Plant Physiol 155: 524-539. DOI: 10.H1104/pp.H110.167H114

Michaud JP, McKenzie CL (2004) Safety of a novel insecticide, sucrose octanoate, to beneficial insects in Florida citrus. Florida Entomol 87: 6-9. http://www.jstor.org/stable/3496797 Accessed: 09-01-2019

Miller R https://reeis.usda.gov/web/crisprojectpages/0227012-tobacco-breeding-and-genetics.html

Moghe GD, Leong BJ, Hurney SM, Jones AD, Last RL (2017) Evolutionary routes to biochemical innovation revealed by integrative analysis of a plant-defense related specialized metabolic pathway. eLife 6:e28468 DOI: 10.7554/elife.28468

Murashige T, Skoog F (1962) A revised medium for rapid growth and bioassay with tobacco tissue culture. Physiol Plant 15: 73-97 
Nadakuduti SS, Uebler JB, Liu X, Jones AD, Barry CS. (2017) Characterization of trichome-expressed BAHD acyltransferases in Petunia axillaris reveals distinct acylsugar assembly mechanisms within the Solanaceae. Plant Physiol 175: 36-50. doi:10.1104/pp.17.00538

Nielsen MT (1989) Registration of KDH 926, KDH 959, KDH 960 tobacco germplasm lines with different levels of trichome exudate constituents. Crop Sci 29: 1584

Ning J, Moghe GD, Leong B, Kim J, Ofner I, Wang Z, Adams C, Jones AD, Zamir D, Last RL (2015) A feedbackinsensitive isopropylmalate synthase affects acylsugar composition in cultivated and wild tomato. Plant Physiol 169:1821-1835. DOI: 10.1104/pp.15.00474

Nottingham SF, Chortyk OT, Stephenson MG (1996) Sugar Esters from Nicotiana Species as potential insecticides against the sweet potato whitefly (Homoptera: Aleyrodidae). J Entomol Sci 31: 331-339. https://doi.org/10.18474/0749-8004-31.3.331

Orians CM (2000) The effects of hybridization in plants on secondary chemistry: implications for the ecology and evolution of plant-herbivore interactions. Am J Bot 87: 1749-56

Patel D, Power JB, Anthony P, Badakshi F, Heslop-Harrison PJS, Davey MR (2011) Somatic hybrid plants of Nicotiana $x$ sanderae $(+)$ N. debneyi with fungal resistance to Peronospora tabacina. Ann Bot 108: 809-819. https://doi.org/10.1093/aob/mcr197

Pental D, Hamill JD, Cocking EC (1984). Somatic hybridisation using a double mutant of Nicotiana tabacum. Heredity 53: 79-83

Puterka GJ, Farone W, Palmer T, Barrington A (2003) Structure-function relationships affecting the insecticidal and miticidal activity of sugar esters. J Econ Entomol 3: 636-44

Rice JH, Mundell RE, Millwood RJ, Chambers OD, Stewart CN, Davies H (2013) Assessing the bioconfinement potential of a Nicotiana hybrid platform for use in plant molecular farming applications. BMC Biotechnol 13: 63 http://www.biomedcentral.com/1472-6750/13/63

Rieseberg LH, Ellstrand NC, Arnold M (1993) What can molecular and morphological markers tell us about plant hybridization. Critical Rev Plant Sci 12: 213-241. https://doi.org/10.1080/07352689309701902

Schilmiller AL, Moghe GD, Fan P, Ghosh B, Ning J, Jones AD, Last RL (2015) Functionally divergent alleles and duplicated loci encoding an acyltransferase contribute to acylsugar metabolite diversity in solanum trichomes. Plant Cell 27: 1002-1017. DOI: 10.1105/tpc.15.00087

Severson RF, Jackson DM, Johnson AW, Sisson VA, Stephenson MG (1991) Ovipositional behavior of tobacco budworm and tobacco hornworm: Effect of cuticular components from Nicotiana species. In: Hedin PA (Ed) Naturally occurring pest bioregulators. Am Chem Soc, Washington DC, , pp 264-277

Severson RF, Johnson AW, Jackson DM, (1985a) Cuticular constituents of tobacco: Factors affecting their production and their role in insect and disease resistance and smoke quality. Recent Adv Tob Sci 11: 105174

Severson, R.F., Arrendale, R.F., Chortyk, O.T., Green, C.R., Thome FA, Stewart, J.L., Johnson, A.W. (1985b) Isolation and characterization of the sucrose esters of the cuticular waxes of green tobacco leaf. J Agric Food Chem 33: 870-875

Simonovska B, Srbinoska M, Vovk I (2006) Analysis of sucrose esters--insecticides from the surface of tobacco plant leaves. J Chromatogr A 1127: 273-277

Slocombe SP, Schauvinhold I, McQuinn RP, Besser K, Welsby NA, Harper A, Aziz N, Li Y, Larson TR, Giovannoni J, Dixon RA, Broun P (2008) Transcriptomic and reverse genetic analyses of branched-chain fatty acid and acyl sugar production in Solanum pennellii and Nicotiana benthamiana. Plant Physiol 148: 1830-46. doi: 10.1104/pp.108.129510

Smeda JR, Schilmiller AL, Kessler A, Mutschler MA (2017) Combination of QTL affecting acylsugar chemistry reveals additive and epistatic genetic interactions to increase acylsugar profile diversity. Mol Breed 37: 1-18

Smith M, Fitzmaurice W, \& Turpen T, Palmer K (2009). Display of peptides on the surface of tobacco mosaic virus particles. Curr Topics Microbiol Immunol 332: 13-31 doi: 10.1007/978-3-540-70868-1_2.

Snyder JC, Carter CD (1984) Leaf trichomes and resistance of Lycopersicon hirsutum and L. esculentum to spider mites (Tetranychus urticae Koch). J Am Soc Hort Sci 109: 837-843

Song Z, Li S, Chen X, Liu L, Song Z (2006) Synthesis of insecticidal sucrose esters. For Studies China. 8: 26. https://doi.org/10.1007/s11632-006-0019-2

Symp. Ser. No. 449, Am Chem Soc Washington DC 
Technical Evaluation Report Sucrose Octanoate Esters - USDA https://www.ams.usda.gov/sites/default/files/media/Sucrose\%20TR\%20Crop.pdf

Wagner GJ (1991) Secreting glandular trichomes: More than just hairs. Plant Physiol 96: 675-679. doi: $10.1104 / p p .96 .3 .675$

Walters DS, Steffens JC (1990) Branched chain amino acid metabolism in the biosynthesis of Lycopersicon pennellii glucose esters. Plant Physiol 93: 1544-51. DOI: 10.1104/pp.93.4.1544

Whitham TG, Martinsen GD, Keim P, Floate KD, Dunge, HS, Pott, BM (1999) Plant hybrid zones affect biodiversity: tools for a genetic-based understanding of community structure. Ecology 80: 416-428 doi:10.1890/00129658(1999)080[0416:PHZABT]2.0.CO;2

Zaitlin D, Mundell R (2006) Nicotiana hybrids and plant varieties for use in production of pharmaceuticals. Patent application US 20060236433 A1 
Table 1 Selected interspecific hybrids and possible major AS acyl group inheritance from both parents.

\begin{tabular}{|c|c|c|c|c|c|}
\hline $\begin{array}{l}\text { Hybrid } \\
\text { number }\end{array}$ & Maternal species & $\begin{array}{l}\text { Major acyl } \\
\text { groups }\end{array}$ & Pollen from: & $\begin{array}{l}\text { Major acyl } \\
\text { groups }\end{array}$ & $\begin{array}{l}\text { Hypothesized major acyl } \\
\text { groups in the hybrids' ASs }\end{array}$ \\
\hline $\begin{array}{l}\mathrm{H} 110 / \\
\mathrm{H} 114\end{array}$ & $\begin{array}{l}\text { N.t. cv. Samsun- } \\
\mathrm{nn}\end{array}$ & 3-MeVal ${ }^{1,2}$ & $\times N$. benthamiana & MeHept ${ }^{a, 3,4,5}$ & 3-MeVal + MeHept \\
\hline H75 & $\begin{array}{l}\text { N. t. SN } 2108 \\
\text { (dark) }\end{array}$ & MeBut ${ }^{b, 1}$ & $\times N$. otophora & $\begin{array}{l}\text { MeHex }^{\mathrm{c}} \\
3-\mathrm{MeVal}^{6}\end{array}$ & MeBut, MeHex, 3-MeVal \\
\hline H87 & $\begin{array}{l}\text { N.t. NC } 297 \text { (flue- } \\
\text { cured) }\end{array}$ & MeBut $^{1}$ & $\times N$. otophora & $\begin{array}{l}\text { MeHex, } \\
\text { 3-MeVal }\end{array}$ & MeBut, MeHex, 3-MeVal \\
\hline H37 & N. excelsior & $\begin{array}{c}\text { Oct, } 5-\mathrm{MeHept} \\
\mathrm{Hept}^{7}\end{array}$ & $\times N$. bigelovii & 3-MeVal ${ }^{3,6}$ & Oct, 5-MeHept,3-MeVal, \\
\hline
\end{tabular}

Table 2 AS acyl group compositions of two commercial tobacco cultivars and their progenitor species. The data in each column represent average of three individually analyzed plants. The underlined acyl groups are the most abundant. The other acyl groups are expressed as mol\% if total.

\begin{tabular}{|c|c|c|c|c|}
\hline Acyl group & $\begin{array}{c}N . \\
\text { sylvestris }^{1} \text { ㅇ } \\
\end{array}$ & $\begin{array}{l}\text { N. tomento- } \\
\text { siformis }{ }^{\hat{}}\end{array}$ & $\begin{array}{l}\text { N.t. Samsun nn } \\
\text { (oriental type) }\end{array}$ & $\begin{array}{c}\text { N.t. K326 } \\
\text { (flue-cured) }\end{array}$ \\
\hline & \multicolumn{4}{|c|}{ mol\% of total } \\
\hline Ac & $\underline{64.3}$ & 25.0 & 30.9 & $\underline{36.5}$ \\
\hline MePro & $-^{a}$ & 1.0 & 9.0 & 6.6 \\
\hline But & 6.6 & 1.9 & 4.5 & 2.0 \\
\hline 2-MeBut & 4.8 & 5.9 & 11.2 & 24.6 \\
\hline 3-MeBut & 1.0 & 3.4 & 10.5 & 19.2 \\
\hline 3-MeVal & 1.9 & $\underline{61.3}$ & 33.9 & 2.6 \\
\hline 4-MeVal & 1.0 & 1.3 & $\overline{\operatorname{tr}^{b}}$ & 1.2 \\
\hline 4-MeHex & 15.6 & - & - & 2.8 \\
\hline 5-MeHex & 4.9 & - & - & 1.3 \\
\hline 5-MeHept & - & - & - & 1.5 \\
\hline 6-MeHept & - & - & - & 1.6 \\
\hline
\end{tabular}

${ }^{a}$ - Not observed, ${ }^{b} \operatorname{tr}-$ Trace amount ${ }^{1}$ The data is from Kroumova et al. 2016 
Table 3 Comparison of the major AS acyl groups in two interspecific hybrids and the parental species. The data of the parental species represent average from three plants. Three individual F1 plants are shown for each hybrid Underlined acyl groups are the most abundant. The numbers represent mol\% of total.

\begin{tabular}{|c|c|c|c|c|c|c|c|c|}
\hline \multirow[t]{2}{*}{ Acyl group } & \multirow{2}{*}{$\begin{array}{c}\text { N.t. Samsun-nn } \\
+ \\
\end{array}$} & \multirow{2}{*}{$\begin{array}{l}\text { N. benth. } \\
\text { o }\end{array}$} & \multicolumn{3}{|c|}{$\underline{\mathrm{H} 110}$} & \multicolumn{3}{|c|}{$\underline{\mathrm{H} 114}$} \\
\hline & & & 1 & 2 & 3 & 1 & 2 & 3 \\
\hline & \multicolumn{8}{|c|}{ mol\% of total } \\
\hline Ac & 32.4 & 16.2 & 0.4 & - & 1.3 & - & - & - \\
\hline MePro & 9.4 & 7.7 & 0.8 & - & 1.6 & 0.9 & - & - \\
\hline 2-MeBut & 11.7 & 0.6 & 0.3 & - & 0.5 & 0.5 & $\operatorname{tr}^{\mathrm{b}}$ & $\operatorname{tr}$ \\
\hline 3-MeBut & 11.0 & 0.2 & 0.6 & - & 1.2 & 1.2 & 0.6 & $\operatorname{tr}$ \\
\hline 3-MeVal & $\underline{35.5}$ & 1.1 & 2.2 & - & 2.4 & 4.0 & 1.5 & 1.3 \\
\hline 4-MeHex & $-^{a}$ & 1.8 & 2.8 & 1.9 & 2.7 & 2.5 & 2.2 & 1.8 \\
\hline 5-MeHex & - & 4.5 & 6.5 & 5.6 & 6.3 & 8.1 & 8.7 & 6.8 \\
\hline 5-MeHept & - & 31.4 & 30.6 & 27.7 & 29.2 & 25.1 & 23.8 & 22.7 \\
\hline 6-MeHept & - & $\underline{36.6}$ & $\underline{55.6}$ & $\underline{64.7}$ & $\underline{54.9}$ & $\underline{57.6}$ & $\underline{63.2}$ & $\underline{67.4}$ \\
\hline
\end{tabular}

a - Not observed; ${ }^{b}$ - Traces

Table 4 AS acyl composition of Hybrids 75 and 87 and their parental species. The data for the dark tobacco are averaged from two plants. The data for the flue-cured tobacco are averaged from three plants. Three individual F1 plants are shown for each hybrid. Underlined acyl groups are the most abundant. The numbers represent mol\% of total.

\begin{tabular}{|c|c|c|c|c|c|c|c|c|c|}
\hline Acyl group & $\begin{array}{c}\text { N.t. KY171* } \\
\text { q } \\
\text { (dark type) } \\
\end{array}$ & N. otophora & 1 & $\underline{\mathrm{H} 75}$ & 3 & 1 & $\underline{\mathrm{H} 87}$ & 3 & $\begin{array}{c}\text { N.t. K326** } \\
+ \\
\text { (flue cured) } \\
\end{array}$ \\
\hline \multicolumn{10}{|c|}{ mol\% of total } \\
\hline Ac & $\underline{47.5}$ & & - & - & 6.7 & - & - & - & $\underline{36.5}$ \\
\hline MePro & 3.8 & & 1.1 & - & 0.7 & 3.3 & - & 2.2 & 6.6 \\
\hline But & 0.9 & & 0.5 & - & 0.3 & 0.5 & - & - & 2.0 \\
\hline 2-MeBut & 24.3 & & 9.5 & 4.3 & 5.3 & 14.4 & 4.8 & 9.0 & 24.6 \\
\hline 3-MeBut & 15.0 & & 11.8 & 6.4 & 7.4 & 12.5 & 4.9 & 8.0 & 19.2 \\
\hline 3-MeVal & 5.8 & $t^{b}$ & $\underline{70.9}$ & $\underline{67.2}$ & $\underline{67.5}$ & $\underline{58.9}$ & $\underline{82.1}$ & $\underline{44.6}$ & 2.6 \\
\hline 4-MeVal & $-c$ & & 2.8 & 2.6 & 3.4 & 2.0 & 2.5 & 1.6 & $1.2^{\mathrm{a}}$ \\
\hline 4-MeHex & $1.4^{\mathrm{a}}$ & $++++^{\mathrm{b}}$ & 0.8 & 1.0 & 0.9 & 0.9 & 1.0 & 1.7 & $1.3^{\mathrm{a}}$ \\
\hline 5-MeHex & $0.5^{\mathrm{a}}$ & $++^{b}$ & - & 1.4 & 1.1 & 0.8 & - & 2.5 & $2.8^{\mathrm{a}}$ \\
\hline 5-MeHept & - & & 0.9 & 4.7 & 4.0 & 2.4 & 1.8 & 7.8 & $1.6^{\mathrm{a}}$ \\
\hline 6-MeHept & - & & 1.6 & 12.4 & 2.7 & 4.4 & 3.0 & 22.6 & $1.5^{\mathrm{a}}$ \\
\hline
\end{tabular}

${ }^{*} N . t$ KY171 is not the exact maternal parent for $\mathrm{H} 75$, but it is representative of dark type tobaccos; ${ }^{* *} N . t . \mathrm{K} 326$ is not the exact maternal parent for $\mathrm{H87}$, but it is representative of flue-cured tobaccos. ${ }^{\mathrm{a}}$ Peak abundance is low and may be missed if small samples are taken for $\mathrm{GC}$ analysis; ${ }^{\mathrm{c}}$-Not detected ; ${ }^{1, \mathrm{~b}}$ The data is from Severson et al. (1991) where acyl groups are not quantified but the order of abundance is given. 
Table 5 AS acyl compositions of $N$. excelsior interspecific hybrids and their parental species. The data for the parental species are averaged from three plants. Three individual H37 F1 plants are shown. The underlined acyl groups are the most abundant. The numbers represent mol\% of total.

\begin{tabular}{|c|c|c|c|c|c|c|c|c|}
\hline \multirow[b]{2}{*}{ Acyl group } & \multicolumn{2}{|c|}{ N. excelsior } & \multirow{2}{*}{$\begin{array}{c}N . \\
\text { bigelovii }^{1} \\
\hat{0}\end{array}$} & \multirow[b]{2}{*}{1} & \multirow{2}{*}{$\frac{\text { Hybrid } 37}{2}$} & \multirow[b]{2}{*}{3} & \multirow{2}{*}{$\begin{array}{l}N . \\
\text { benthamiana } \\
\delta\end{array}$} & \multirow[t]{2}{*}{$\begin{array}{c}N . \\
\text { excelsiana* }\end{array}$} \\
\hline & 11-S-19-1 & 90-S-19-2 & & & & & & \\
\hline & \multicolumn{8}{|c|}{ mol\% of total } \\
\hline Ac & 1.3 & 8.6 & 17.0 & 9.6 & 6.5 & 1.5 & 16.0 & - \\
\hline MePro & 1.6 & 2.2 & 9.6 & 3.8 & 4.6 & 3.4 & 7.6 & - \\
\hline But & 1.0 & 1.3 & 0.1 & 1.1 & 3.1 & 2.2 & 0.1 & - \\
\hline 2-MeBut & 7.3 & 13.6 & 19.5 & 1.6 & 7.6 & 4.3 & 0.6 & - \\
\hline 3-MeBut & 0.4 & 1.7 & 5.4 & 2.1 & 6.0 & + & 0.2 & - \\
\hline 3-MeVal & 0.7 & - & 45.9 & 5.1 & $\underline{20.5}$ & 5.2 & 1.1 & - \\
\hline 4-MeVal & $-{ }^{a}$ & - & - & 1.4 & $\overline{1.6}$ & 2.1 & 0.9 & - \\
\hline 4-MeHex & $\operatorname{tr}^{b}$ & $\operatorname{tr}$ & 0.1 & 4.0 & 7.7 & 10.0 & 1.8 & - \\
\hline 5-MeHex & $\operatorname{tr}$ & $\operatorname{tr}$ & 0.3 & 7.1 & 8.0 & 11.8 & 4.4 & - \\
\hline 5-MeHept & 31.3 & 15.9 & 0.6 & 21.8 & 19.8 & $\underline{30.8}$ & 31.1 & 36.9 \\
\hline 6-MeHept & 3.7 & 1.2 & 1.6 & $\underline{42.5}$ & 14.5 & 28.6 & $\underline{36.2}$ & $\underline{63.1}$ \\
\hline Hept & 14.5 & 6.8 & - & - & - & - & - & - \\
\hline Oct & $\underline{38.2}$ & $\underline{48.7}$ & - & - & - & - & - & - \\
\hline
\end{tabular}

${ }^{a}$ - Not observed; - ${ }^{b}$ tr-traces; -; ${ }^{*}$ The data was generated from pooled leaf extract from several plants; ${ }^{1}$ The data is from Matsuzaki et al. (1989)

Table 6 AS acyl composition of Alatae hybrids and their parental species. The data for N. alata and N. $\times$ sanderae are averaged from three plants. Three individual plants from two representative hybrids are shown. All species in the table were involved in the creation of the PO hybrids. The underlined acyl groups are the most abundant. The numbers represent mol\% of total.

\begin{tabular}{|c|c|c|c|c|c|c|c|c|c|c|}
\hline \multirow[t]{2}{*}{$\begin{array}{l}\text { Acyl } \\
\text { group }\end{array}$} & $\begin{array}{l}\text { N. } \\
\text { alata }^{1}\end{array}$ & $\begin{array}{l}N . \\
\text { forgetiana }{ }^{2}\end{array}$ & $\begin{array}{l}\text { N. } \times \\
\text { sanderae }^{1}\end{array}$ & \multicolumn{3}{|c|}{ P067* } & \multicolumn{3}{|c|}{ PO72** } & \multirow{2}{*}{$\begin{array}{l}\text { N.langs } \\
\text { dorfii }\end{array}$} \\
\hline & $q$ & & & 1 & 2 & 3 & 1 & 2 & 3 & \\
\hline \multicolumn{11}{|c|}{ mol\% of total } \\
\hline Ac & $\underline{23.9}$ & & 21.5 & - & - & - & - & - & - & \\
\hline MePro & 14.3 & & 3.8 & 4.2 & 3.4 & 5.0 & 6.6 & 7.1 & 5.7 & + \\
\hline But & 7.4 & & 3.6 & - & - & - & 4.0 & 4.8 & 4.2 & \\
\hline 2-MeBut & 20.4 & $\underline{+++}^{\mathrm{b}}$ & 30.2 & 4.3 & 5.5 & 4.9 & 23.2 & 35.9 & $\begin{array}{c}23 . \\
1\end{array}$ & + \\
\hline 3-MeBut & 6.9 & & 0.9 & 3.7 & 3.4 & - & 4.2 & 2.4 & - & \\
\hline 3-MeVal & 3.9 & & 1.9 & - & - & - & - & - & - & \\
\hline Hex & 6.2 & & 3.5 & - & 5.0 & - & 6.8 & 5.4 & 5.7 & \\
\hline
\end{tabular}




\begin{tabular}{|c|c|c|c|c|c|c|c|c|c|c|}
\hline 4-MeHex & $-^{a}$ & + & - & - & - & - & - & - & - & \\
\hline 5-MeHex & - & + & - & - & - & - & - & - & - & \\
\hline Hept & - & & - & - & 4.7 & 6.7 & 5.8 & 2.9 & 3.6 & \\
\hline Oct & 16.8 & & $\underline{34.7}$ & 87.8 & 73.0 & $\underline{83.4}$ & 44.0 & $\underline{38.9}$ & $\frac{54}{\underline{4}}$ & $\underline{+++}$ \\
\hline Non & - & & - & 4.2 & 5.0 & - & 5.2 & 2.6 & 3.3 & \\
\hline
\end{tabular}

a - not observed; ${ }^{b}+$-not quantified, but 2-MeBut in N. forgetiana and Oct in N. langsdorfii are designated as major groups; *SE acyl composition of PO67 is similar to that of POs 15, 69, 70, 81, 101, and 120.**SE acyl composition of PO72 is similar to that of POs 5, 33, 71, 80, 94, and 96; ${ }^{1}$ Kroumova et al. 2016; ${ }^{2, b}$ Severson et al. 1991; ${ }^{3, b}$ Cutler et al. 1992

Table 7 AS acyl composition of horticulture hybrids "Thinkerbell", "Baby Bella" and "Whisper". N. alata and N. x sanderae are some of the parental species (on the basis of the commercial providers' information https://www.gardenersworld.com/plants/nicotiana-alata-tinkerbell/; http://www.robsplants.com/plants/NicotSande). The data for $N$. alata and $N . \times$ sanderae are averaged from three plants. Individual F1 plants from each hybrid are shown. The underlined acyl groups are the most abundant. The numbers represent mol\% of total. 


\begin{tabular}{|c|c|c|c|c|c|c|c|c|c|c|c|}
\hline \multirow{2}{*}{ Acyl group } & \multirow{2}{*}{$\begin{array}{l}N . \\
\text { alata }^{1} \\
\quad *\end{array}$} & \multirow{2}{*}{$\begin{array}{l}\text { N. } \times \\
\text { sanderae }^{1} \\
*\end{array}$} & \multicolumn{4}{|c|}{ "Thinkerbell" } & \multicolumn{3}{|c|}{ "Baby Bella" } & \multicolumn{2}{|c|}{ "Whisper" } \\
\hline & & & 1 & 2 & 3 & 1 & 2 & 3 & 1 & 2 & 3 \\
\hline \multicolumn{12}{|c|}{ mol\% of total } \\
\hline Ac & 23.9 & 21.5 & 32.0 & - & 13.0 & 21.5 & - & 4.4 & 3.3 & 3.0 & 1.4 \\
\hline Pro & - & - & 5.4 & - & 3.7 & 5.3 & - & - & - & - & - \\
\hline MePro & 14.3 & 3.8 & 13.3 & 3.1 & 12.2 & 13.8 & 0.5 & 4.7 & 6.3 & 5.5 & 1.5 \\
\hline But & 7.4 & 3.6 & 0.9 & 1.5 & 2.0 & 9.7 & 1.1 & 4.4 & 3.7 & 2.5 & 1.0 \\
\hline 2-MeBut & 20.4 & 30.2 & $\underline{32.9}$ & $\underline{38.4}$ & $\underline{37.3}$ & - & 14.7 & 22.0 & $\underline{23.8}$ & 20.8 & 21.3 \\
\hline 3-MeBut & 6.9 & 0.9 & 2.7 & 2.3 & 3.2 & - & 1.3 & 2.6 & 3.8 & 3.5 & 3.2 \\
\hline 3-MeVal & 3.9 & 1.9 & 1.2 & 3.6 & 4.8 & 6.8 & 0.7 & - & 6.2 & 4.6 & 2.1 \\
\hline 4-MeVal & - & - & $\operatorname{tr}$ & 1.2 & $\operatorname{tr}$ & 0.7 & 0.8 & - & 3.0 & 2.2 & 0.6 \\
\hline Hex & 6.2 & 3.5 & 0.8 & 2.6 & 1.5 & 4.6 & 6.3 & 3.1 & 3.5 & 2.9 & 3.0 \\
\hline 4-MeHex & - & - & 0.5 & - & 0.3 & - & - & - & 5.6 & 3.4 & 1.0 \\
\hline 5-MeHex & & & 0.4 & - & 0.3 & - & - & - & - & - & 0.8 \\
\hline Hept & - & - & 0.3 & 2.0 & 0.7 & 1.7 & 4.5 & 1.9 & 4.1 & 2.7 & 1.7 \\
\hline 5-MeHept & - & - & - & - & - & - & 0.4 & - & 4.2 & 2.4 & 1.5 \\
\hline 6-MeHept & - & - & - & - & - & - & 0.5 & - & 3.5 & 2.7 & 1.5 \\
\hline Oct & 16.8 & 34.7 & 7.2 & 34.5 & 16.3 & $\underline{31.2}$ & $\underline{57.9}$ & $\underline{37.8}$ & 12.7 & 30.8 & 45.1 \\
\hline Non & - & - & 1.0 & 5.7 & 2.2 & 3.5 & 9.6 & 5.0 & 4.2 & 3.8 & 5.0 \\
\hline Dec & - & - & 1.1 & 4.0 & 2.1 & 0.9 & 1.3 & 13.1 & 8.0 & 5.8 & 7.1 \\
\hline Laur & - & - & 0.3 & 1.0 & 0.4 & 0.3 & 0.4 & 0.9 & 3.9 & 3.3 & 2.9 \\
\hline
\end{tabular}

a - Not observed; ${ }^{1}$ Kroumova et al. 2016 


\section{Figure legends}

Fig. 1. Phenotypes of two N. tabacum cv. Samsun-nn $\times N$. benthamiana F1 hybrids, of two $N$. tabacum $\times N$. otophora F1 hybrids, and of $N$. excelsior $\times N$. bigelovii F1 hybrid. 


\section{Electronic supplementary materials}

Title:

Patterns of inheritance of acylsugar acyl groups in selected interspecific hybrids of genus Nicotiana

\section{Authors:}

Antoaneta B. M.-Kroumova, Ivan Artiouchine., Victor Korenkov, George J. Wagner

Journal:

Journal of Plant Research

\section{Corresponding author:}

Antoaneta B. M.-Kroumova

(Kentucky Tobacco Research and Development Center, 1401 University Dr., College of Agriculture, University of Kentucky, Lexington, KY 40546-0236, USA)

Tel: +859-257-2409

FAX: +859-323-1077

E-mail: amihaylo@uky.edu 


\section{Content:}

\section{Figs. S1-S6}

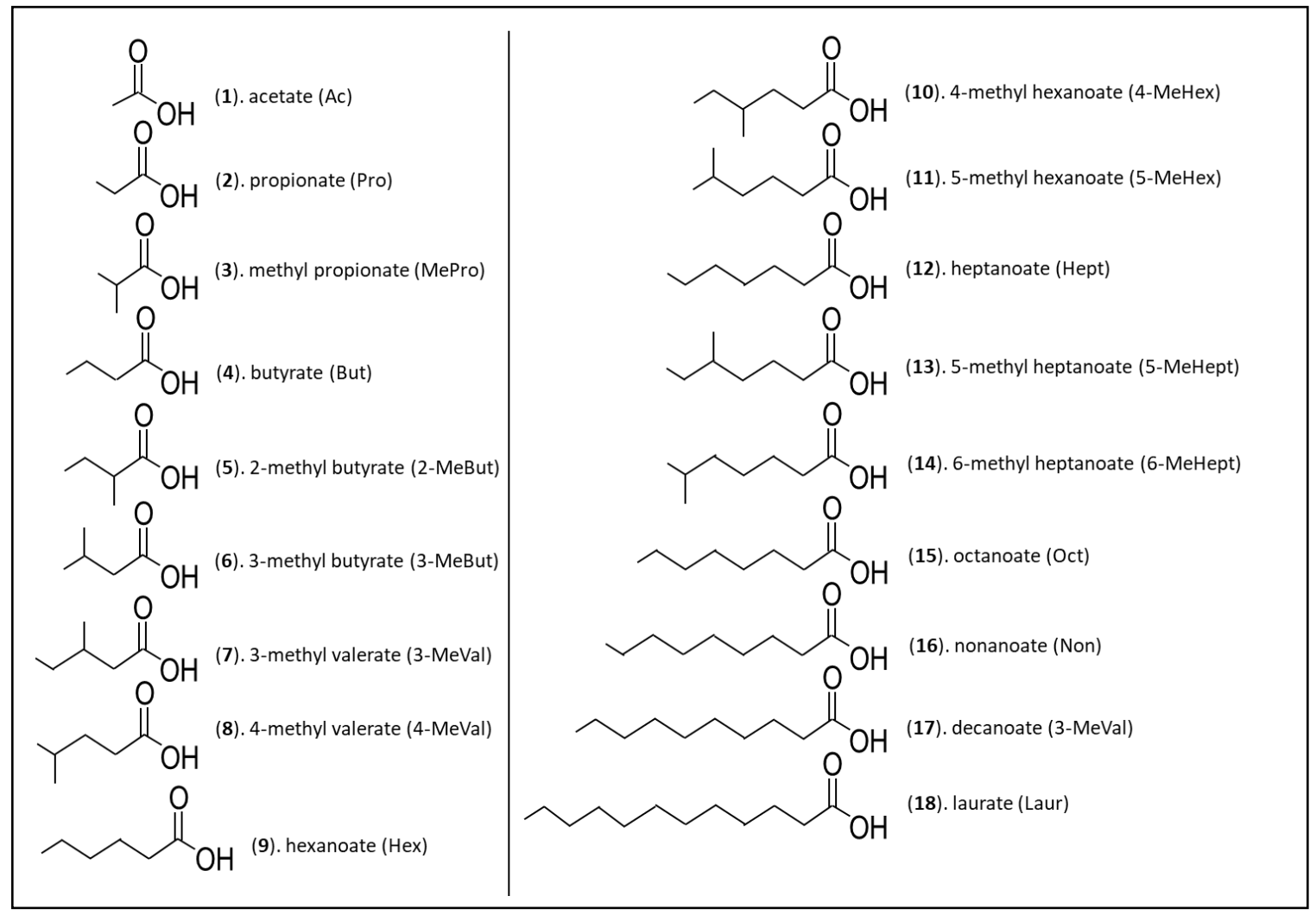

Figure S1 Linear structure of all acyl groups found.

An abbreviation for each group is given in parenthesis. The figure is modified from Kroumova et al. (2016). 


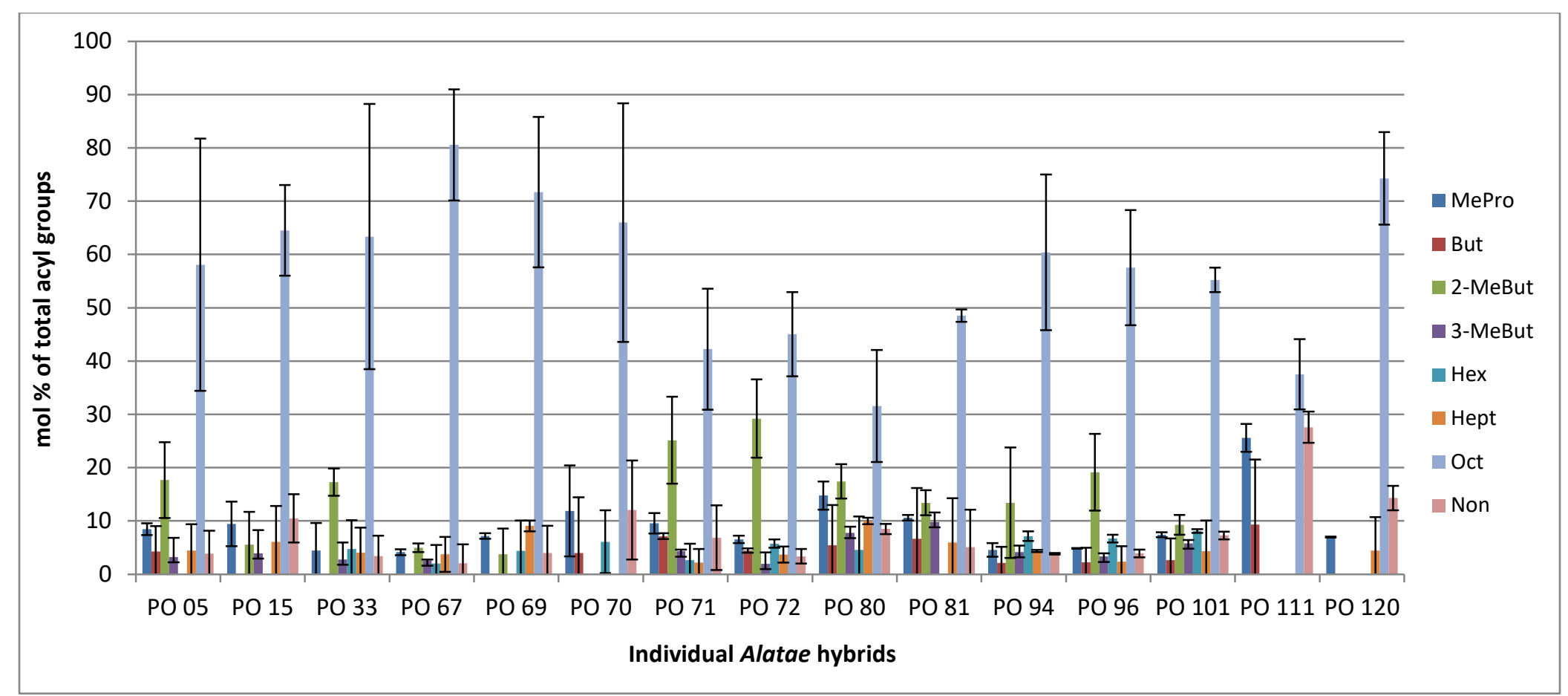

Figure S2 AS acyl group composition of Alatae hybrids

Peak areas of acyl butyrates were converted to mols. The values are expressed as mol\% of total. Three separate plants from each hybrid line were analyzed. The columns present the average value, and the error bars- standard deviation. 


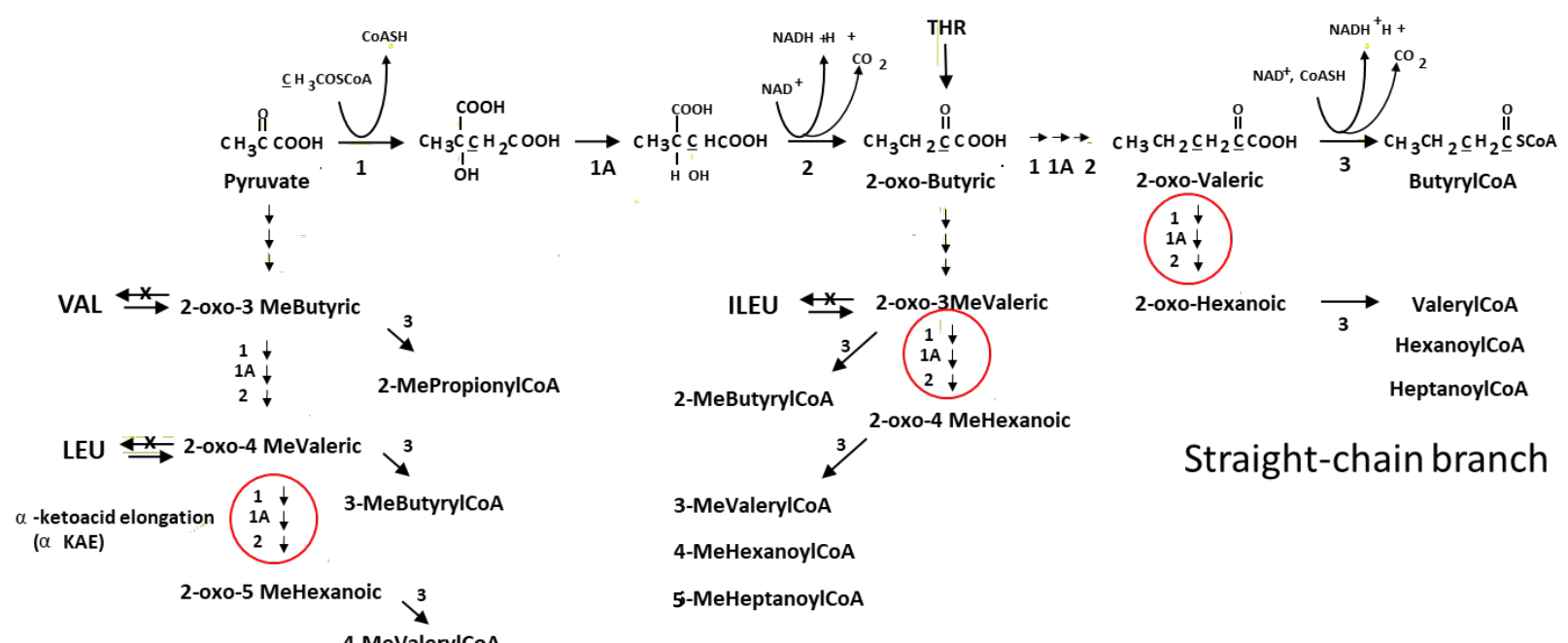

Anteiso-chain branch

Iso-chain branch

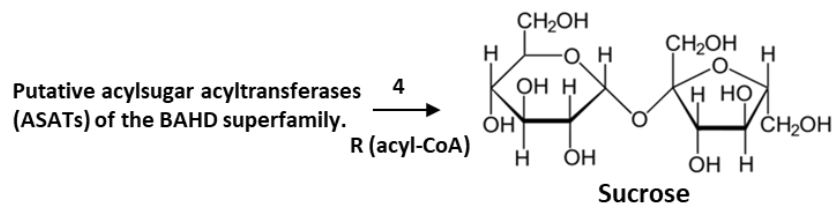

Figure S3 Suggested pathways for synthesis of acyl-CoA groups

This figure is modified from Kroumova et al. (1994). Structurally, acyl groups possess either iso-branched carbon chain, anteiso-branched carbon chain or straight carbon chain. Acyl groups with iso-chain carbon skeleton come from modified valine (Val) and leucine (LEU) metabolism/catabolism; acyl groups with anteiso-chain carbon skeleton come from modified isoleucine (ILEU) metabolism/catabolism, and acyl groups with straight-chan carbon skeleton come from pyruvate- or threonine (THR) -derived 2-oxobutyrate (Kandra et al. 1990). Synthesis of the acyl groups shown is proved to occur via one-carbon chain elongation called alpha-ketoacid elongation ( $\alpha$-KAE - circled in red)(Kroumova et al., 1994) in $N$. benthamiana, N. glutinosa, N. gossii and petunia (Kroumova et al. 1994, 2009). Enzymes catalyzing reaction 1,1A, 2 and 3 are assumed to be 1: 2-isopropylmalate synthase (IPMS) (condensation), 1A: 3 isopropylmalate dehydratase (isomerization), 2: 3-isopropylmalate dehydrogenase (oxidative decarboxylation), 3: 2-oxo-isovalerate dehydrogenase (oxidative decarboxylation) or branched-chain ketoacid dehydrogenase (BCKD) ( Kandra et al, 1990; Mooney et al., 2002). 4: In genus Solanum and in petunia the assembly of acyl sugars was shown to involve numerous acyltransferases (reaction 4) that attach the acyl-CoAs to the sucrose or glucose moieties (Moghe et al, 2017, Nadakuduti et al., 2017, references are given in the manuscript), but orthologous acyltransferase genes have not been reported for Nicotiana species. In Nicotiana species enzymes catalyzing acyl sugar assembly (reaction 4) are assumed to be also acyltransferases.

Kandra G, Severson R, Wagner GJ (1990) Modified branched-chain amino acid pathways give rise to acyl acids of sucrose esters exuded from tobacco leaf trichomes. Eur J Biochem.188: 385-91.

Mooney BP, Miernyk JA, Randall DD (2002) The complex fate of alpha-ketoacids. Annu Rev Plant Biol 53: 357-75. 